\title{
A interlocução público-privada na produção de medicamentos para o SUS.
}

\author{
Giana Marcellini \\ SINDUSFARQ \\ contato@sindusfarq.com.br
}

O SINDURFARQ tem feito uma parceria muito interessante com a Secretaria de Estado da Saúde, visto que não é sempre que o setor privado é chamado para 'conversar' e com o atual secretário de saúde essa abertura tem sido muito interessante.

Então aqui será discutido sobre a interlocução público e privada na produção de medicamentos para o SUS. A SINDUSFARQ que é o sindicato que representa as indústria afarmacêuticas, químicas, cosméticas e de biotecnologia de Minas Gerais. Possui 90 empresas associadas e uma base sindical de 720 indústrias. Neste contexto a Biotecnologia não se refere apenas aos biofármacos. Biotecnologia se refere a tudo que trabalha com o ambiente biológico. Dessas 90 empresas, 19 são de biotecnologia, 50 são farmacêuticas, 25 de cosméticos e 8 químicas. Todas indústrias farmacêuticas de Minas Gerais estão associadas ao SINDUSFASRQ. Minas Gerais possui 230 empresas cosméticas, havendo ainda uma mobilização inicial para a sindicalização destas.

Como citado, Minas Gerais possui 50 indústrias farmacêuticas. Normalmente, são indústrias de pequeno e médio porte, principalmente médio porte. São fabricantes de medicamentos novos, similares, genéricos e fitoterápicos. A indústria de medicamentos fitoterápicos é forte aqui em Minas Gerais. Em 2009, essas indústrias atingiram um faturamento de 2 bilhões de dólares. Com relação ao emprego, foi assinalado um aumento de 3,2\%, indicando que esta indústria empregou mais. A indústria farmacêutica de uma maneira geral não sentiu a crise como empresas de outros setores.

Além da produção de medicamentos tem-se uma indústria muito forte no que é chamado de diagnóstico. Essas indústrias estão principalmente na parte de biotecnologia, equipamentos médicos como o Raio X e produtos para a saúde como hidroxiapatita, lentes intra oculares, válvulas cardíacas etc. Existem muitas indústrias desse tipo em torno de Belo Horizonte, inclusive indústrias multinacionais. Algumas indústrias multinacionais vêm para Belo Horizonte por causa da expertise da biotecnologia de Minas Gerais.

A FUNED- Fundação Ezequiel Dias está trabaIhando fortemente no desenvolvimento de biofármacos. Existem alguma linha de fomento para o estímulos dos setores públicos e privados no Brasil. No Estado de Minas Gerais, a biotecnologia foi considerada um projeto estruturador. Na verdade a Secretaria de Ciências e Tecnologia como política de Estado e como política desse governo, elegeu quatro setores para serem estimulados. Não somente setores industriais, mas a parte acadêmica, centros de pesquisa e setores industriais. Então tem-se como exemplos desses estímulos e da visão do Estado para este setor o Programa de Pesquisa para o SUS da FAPEMIG, PPSUS.

Assim , a FAPEMIG foi a principal instituição que destinou recursos para a pesquisa de produtos para o SUS. Iniciou 2003 com o financiamento de R\$ 360.000 com 11 projetos e em 2009 esse valor foi elevado para $\mathrm{R} \$ 18.000 .000,00$ para poder incentivar o setor público privado e academias, inclusive com editais que exigem parcerias entre universidades e empresas para produção de produtos para o SUS. Um outro projeto, o Projeto Estruturador investiu nos últimos três anos 8,8 milhões de Reais para a biotecnologia. Esse investimento existe tanto para o setor privado como tem um centro de bioinformática no René Rachou, Fio Cruz Minas Gerais, tem um banco de células no Hemominas e algumas pesquisas da FUNED. 
Quanto as linhas de fomentos federais tem-se como principal expoente o BNDES - Banco Nacional do Desenvolvimento, colocando 3 bilhões de Reais até 2012 na montagem de multinacionais farmacêuticas. Este banco possui programa PROFARMA que investe no setor farmacêutico e tanto na parte de desenvolvimento como na parte de fusões e aquisições para transformar o setor farmacêutico de biotecnologia em um grande setor brasileiro. Esse investimento é importante pelo fato de que este setor é estratégico para a economia brasileira.

O setor farmacêutico brasileiro não está entre os setores intensivos de P\&D entre 2003 e 2005, segundo PINTEC do IBGE. Ele não era estimulado na parte de $P \& D$ e não existiam incentivos para fazer pesquisa e desenvolvimento nesta parte. Sabe-se que as indústrias farmacêuticas, principalmente, as nacionais são grandes copiadoras de produtos. Mas mesmo para ser copiadora tem que se fazer a transferência de tecnologia e é necessário inovar também. Antes de 2006 isso era proibido, pois não existia uma lei em que você poderia estar investindo em inovação junto com as empresas.

Porque o Brasil é um grande fabricador de papers e não de patentes? Porque os investimentos sempre foram unicamente na academia. A lei da inovação de 2006 é que permitiu fazer aplicações do governo e estimular pesquisa e desenvolvimento dentro das empresas, principalmente com as parcerias públicas e privadas.

No nível nacional, em 2006, 11 empresas farmacêuticas foram beneficiadas com o valor de 20,7 milhões de reais. Em 2007, 13 empresas totalizando um valor de 34 milhões de reais. Mas o número de empresas ainda é muito pequeno.

Existe no Brasil algumas linhas de investimentos no setor publico e privado para o desenvolvimento de pesquisa. A FINEP com alguns recursos reembolsáveis disponibilizou 200 milhões de reais entre 2005 e 2008. O BNDES Reembolsáveis disponibilizou aproximadamente 31 milhões ente 2007 e 2008. O FINEP Subvenção econômica (significa que não precisa existir o reembolso, o antigo fundo perdido) disponibilizou aproximadamente 110 milhões entre 2006 e 2008. Os Fundos setoriais, com relação ao CT-Saúde, houve um desembolso de apenas 73 milhões de reais.

Em 2007, o governo federal instituiu o Comitê Nacional de Biotecnologia e instituiu a política de desenvolvimento da biotecnologia. E na parte de saúde colocou esses medicamentos como medicamentos que seriam priorizados no investimento de desenvolvimento no investimento de transferência, no desenvolvimento nacional.Entre

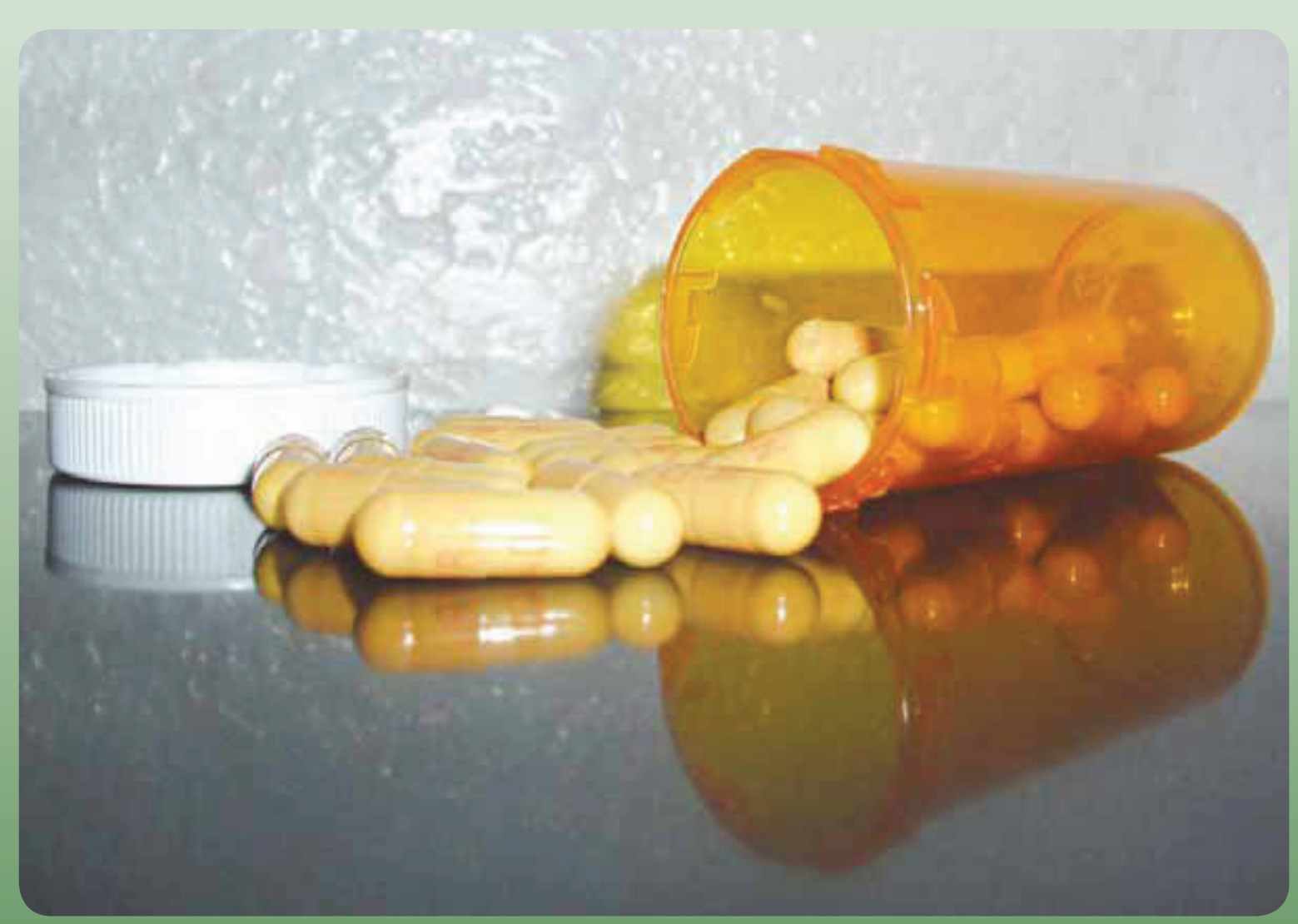


os principais medicamentos estão: hormônio de crescimento humano e bovino (somatotrofina), insulina humana, calcitonina, LH-RH, somatostatina, gonadotrofina coriônica (HCG) e sérica (PMSG), LH (Hormonio luteinizante bovino e suíno), FSH (hormônio folículo estimulante humano e bovino), IGF-I (Fator de crescimento insulina dependente), Interferon alfa, Interferon beta, Toxina Butolínica.

Apesar de produzirmos nacionalmente a insulina, esses medicamentos são a maioria importados. Desde 2007 o Brasil tem uma política para que esses medicamentos sejam produzidos internamente.

Então chega-se na questão do poder de compra do governo. Em Minas Gerais, tem-se um total de gastos para medicamento de 470 milhões. Desses 470 milhões, 120 milhões são para medicamentos básicos e 350 milhões para medicamentos de alto custo. Medicamentos de alto custo são normalmente importados, patenteados, caros e basicamente um único fabricante. Então gastase a maior parte do dinheiro público com os medicamentos de alto custo.

Cerca de $80 \%$ dos medicamento da farmácia básica são produzidos em Minas Gerais. Como exemplo dos produtos tem-se: insulina, metiformina, antihipertensivos (Enalapril), antibióticos e anti inflamatórios (amoxicilina e cefalexinas). As 50 indústrias de medicamentos produzem commodities. São os medicamentos da farmácia básica. Não se produz nenhum medicamento de alto custo, exceto a insulina que foi a grande questão da biotecnologia em Minas Gerais, porque a Biobrás, vinda da UFMG fez a sintetize deste produto. Só existiam 3 indústrias de insulina no mundo. A Biobrás era uma delas que inclusive vendia para o governo. Porém, há uns três anos a empresa Novo Nordisk comprou a Biobrás. Então, hoje tem-se uma grande empresa multinacional que é a Novo Nordisk que produz insulina e que inclusive investiu muito na fabrica dela em Montes Claros e transformou a planta que está produzindo insulina para exportação. A planta mundial dela é aqui em Montes Claros, dando emprego e gerando renda. Fora disso são medicamentos normais que são produzidos em Minas Gerais.

A política de saúde e desenvolvimento produtivo (PDP) trouxe um grande desafio: o governo usa o poder de compra para estimular a produção nacional. O governo federal está investindo, o governo estadual está investindo e isso é uma questão importante. Existe o Complexo Industrial da Saúde que visa produzir medicamentos estratégicos do SUS

A importância da parceria público e privada foi vista no caso da FUNED, pois quando abriu uma concorrência dos medicamentos que eles tinham condições de produzir foram ofertados medicamentos pelas empresas privadas a um preço até abaixo do preço de custo. Mas com certeza, o custo de produção era com certeza mais baixo do que de outras empresas conseguiam ter. Então a concorrência é sempre válida, pois quanto mais concorrência melhor.

A questão da tributação é um peso na comercialização e na produção de medicamentos. Hoje tem-se em impostos algo em torno de $32 \%$ que a indústria paga para a produção de medicamentos. No Estado de Minas Gerais, os produtos farmacêuticos foram um dos primeiros produtos a ter substituição tributária e não tem incentivo nenhum. Agora $\mathrm{O}$ governo está fazendo convênio com São Paulo para a substituição tributária. Então, não se percebem incentivos para estimular pesquisas ou mesmo a produção de medicamentos nacionais.

Minas Gerais é um ambiente favorável para investimento deste setor. Existe uma grande diversidade de plantas que possibilitam desenvolvimento de novos produtos. Diversas empresas mineiras tem parceria com as universidades, principalmente, a Universidade Federal de Viçosa, para o desenvolvimento de produtos a base de plantas. Existe a política industrial de fitoterápicos, mas não é percebido nenhum incentivo para as empresas estarem produzindo e aproveitando a biodiversidade brasileira e a biodiversidade mineira com as plantas do cerrado.

Tem-se a questão das farmácias vivas que é interessante colocar como uma modo de incentivar esse setor aqui em Minas, colocando a industrialização dos fitoterápicos. As indústrias de Minas são indústrias muito fortes na parte de fitoterápicos. Tem indústrias de mais de 90 anos que produzem fitoterápicos e tem empresários interessados em investir nos parques. Tem o SINDUSFARQ como fator de agregação e estímulo para as indústrias estarem investindo em pesquisa, investindo em desenvolvimento. Também existe o Minas Biotec que é um pólo de biotecnologia. Minas é o primeiro pólo de biotecnologia com a região metropolitana no setor saúde, Viçosa na parte fitoterápica e o triângulo mineiro na parte animal.

As empresas de Minas estão altamente interessadas em desenvolver produtos de alto custo para diminuir a questão do custo com os gastos do governo nos produtos de alto custo. É muito importante colocar que quando os produtos são produzidos em Minas, o desenvolvimento fica em Minas Gerais, assim como a expertise, a geração de mais empregos e mais impostos. É necessário investir nas empresas de Minas Gerais para o desenvolvimento deste importante setor. 